\title{
Design and Implementation of an Electric Differential for Traction Application
}

\author{
A. Haddoun ${ }^{1,2}$, M.E.H. Benbouzid ${ }^{1}$, D. Diallo ${ }^{3}$, R. Abdessemed ${ }^{4}$, J. Ghouili $^{5}$ and K. Srairi ${ }^{6}$ \\ ${ }^{1}$ University of Brest, EA 4325 LBMS - Rue de Kergoat, CS 93837, 29238 Brest Cedex 03, France \\ ${ }^{2}$ University of Oum El Bouaghi, 04000 Oum El Bouaghi, Algeria \\ ${ }^{3}$ University of Paris Sud P11, Supéléc, UMR 8507 LGEP, 91192 Gif-Sur-Yvette, France \\ ${ }^{4}$ University of Batna, 05000 Batna, Algeria \\ ${ }^{5}$ University of Moncton, Moncton, New Brunswick, Canada \\ ${ }^{6}$ University of Biskra, 07000 Biskra, Algeria \\ E-mail: Mohamed.Benbouzid@univ-brest.fr
}

\begin{abstract}
The use of an Electric Differential (ED) constitutes a technological advance in vehicle design along with the concept of more electric vehicles. EDs have the advantage of replacing loose and heavy mechanical differentials and transmissions with lighter and smaller electric motors directly coupled to the wheels via a single gear or an in-wheel motor. This paper deals then with an Electric Differential System (EDS) for an Electric Vehicle (EV) directly driven by dual induction motors in the rear wheels. A sensorless control technique is preferred to a position or speed encoder-based control one to reduce the overall cost and to improve the reliability. The EDS main feature is the robustness improvement against system uncertainties and road conditions. The EDS control performances are validated through experiments on a dSPACE-based test bench. The experimental results show that the proposed controller is able to track the speed reference and the curvature angle with good static and dynamic performances.
\end{abstract}

Index Terms-Electric Vehicle (EV), induction motor, Electric Differential (ED), traction control, speed estimation, experimental implementation.

\section{INTRODUCTION}

Generally, in most EV propulsion applications, an AC motor is connected to the wheels by reduction gears and a mechanical differential. In some vehicle drive arrangements, high-speed low-torque wheel motors requiring gear reduction are used. In these cases, either a gear-motor assembly is mounted inside the wheel or a chassis-mounted motor is connected to the wheel through gear reduction. Further simplification of the vehicle drive arrangement results in elimination of the gear being interposed between the motor and the wheel. The above condition calls for the use of an electric differential (no mechanical gear) [1-2]. ED-based EVs have advantages over their classical counterparts with a central motor. Indeed, mounting the motors directly on the wheels simplifies the mechanical layout. The EDS will reduce the driveline components, thus reducing the mass and improving the overall reliability and efficiency.

This paper aims to present an innovative controller for an EV with improved driving characteristics maintaining the crucial advantages of high efficiency and local zero emissions. This vehicle is considered to be one of the most likely candidates for personal transportation in cities where air quality and traffic problems are quite demanding. In this context we proposed a simplified EDS, without expensive sensors, for an EV driven by dual rear wheels and with two induction motor drives (one for each wheel) [2]. In this case, the ED will manage the speed difference between the two wheels when cornering. The proposed EDS have a control loop to improve driving safety and stability. Indeed, the wheel speeds are finely tuned using the Model Reference Adaptive System (MRAS) approach for robustness purposes against external disturbances and system uncertainties.

\section{CONTROL SYSTEM DESCRIPTION}

Figure 1 shows a block diagram of the developed EV propulsion control. The control system inputs are the speed reference based on the throttle position and the steering wheel angle defined by hand wheel rotation. The ED distributes the speed to the left and right wheel drive motors. The propulsion control system is implemented on a dSPACE digital signal processor DS1103 [3]. This platform has high-power calculation capability, notably with the presence of various dedicated multipliers, and parallel processing [3-4]. These features are required by the time-critical and intensive computing tasks performed by the propulsion control system. In addition, Fig. 1 illustrates the implemented system (electric and mechanical components) in the Matlab-Simulink ${ }^{\circledR}$ environment. It should be noted that the two inverters share the same DC bus whose voltage is supposed to be stable. Regenerative braking is not taken into account in this paper.

In addition, Fig. 1 illustrates the implemented system (electric and mechanical components) in the MatlabSimulink $^{\circledR}$ environment. It should be noted that the two inverters share the same DC bus whose voltage is supposed to be stable. Regenerative braking is not taken into account in this paper. The proposed control system principle could be summarized as follows: 1) A MRAC approach is used to control each motor torque; 2) The speed of each rear wheel is controlled using speed difference feedback. Since the two rear wheels are directly driven by two separate motors, the speed of the outer wheel will need to be higher than the speed of the inner wheel during steering maneuvers (and vice-versa). 


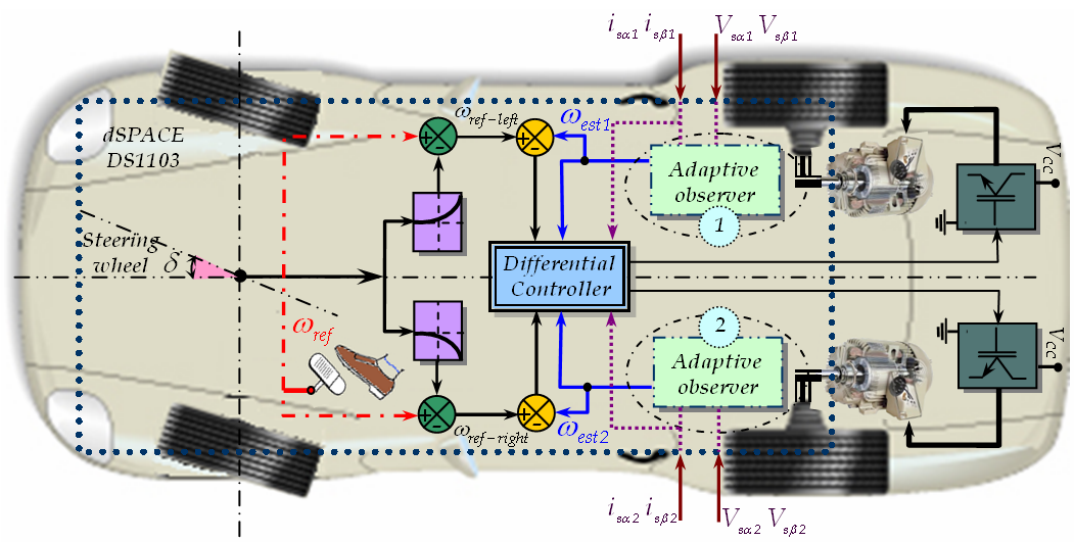

Fig. 1. Propulsion control chip architecture implemented on a dSPACE DS1103.

This condition can be easily met if the speed estimator is used to sense the angular speed of the steering wheel. The common reference speed $\omega_{\text {ref }}$ is then set by the accelerator pedal command. The actual reference speed for the left drive $\omega_{\text {ref-left }}$ and the right drive $\omega_{\text {ref-right }}$ are then obtained by adjusting the common reference speed $\omega_{\text {ref }}$ using the output signal from the adaptive observer speed estimator. If the vehicle is turning right, the left wheel speed is increased and the right wheel speed remains equal to the common reference speed $\omega_{\text {ref. }}$. If the vehicle is turning left, the right wheel speed is increased and the left wheel speed remains equal to the common reference speed $\omega_{\text {ref }}[2-5]$.

\section{THE ELECTRIC DIFFERENTIAL AND ITS IMPLEMENTATION}

Usually, a driving trajectory is quite enough for an analysis of the vehicle system model. We have therefore adopted the Ackermann-Jeantaud steering model as it is widely used as driving trajectory. In fact, Ackermann steering geometry is a geometric arrangement of linkages in the steering of a car or other vehicle designed to solve the problem of wheels on the inside and outside of a turn needing to trace out circles of different radii. Modern cars do not use pure Ackermann-Jeantaud steering, partly because it ignores important dynamic and compliant effects, but the principle is sound for low speed maneuvers [1-6] (Fig. 2).

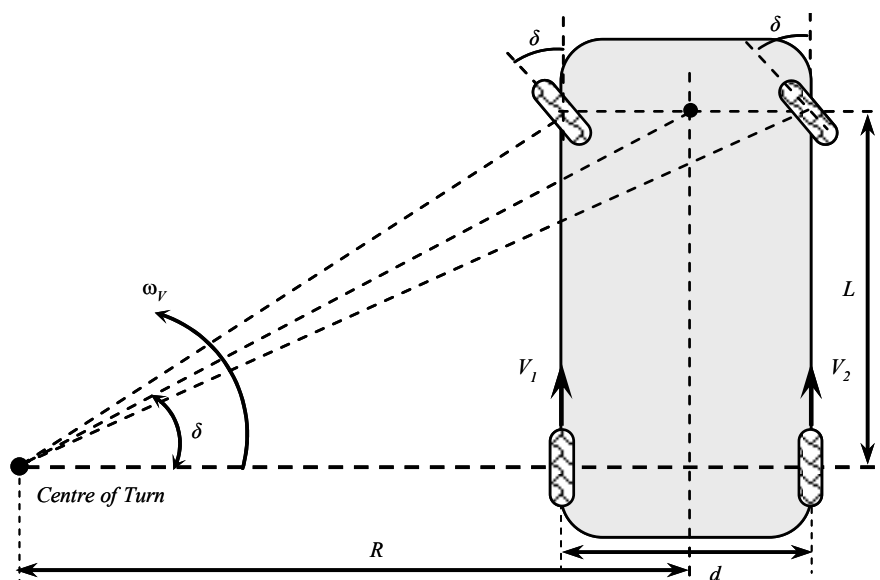

Fig. 2. Driving trajectory model
One of the most important elements of the controller is the ED module. This module allows removing from the propulsion system the mechanical differential and transmission that makes the propulsion train completely electric. This all electric propulsion train has several advantages over traditional mechanical propulsion trains; it uses several electric motors, one for each driving wheel allowing independent control of each wheel. By having independent control of each wheel several features can be easily added to the propulsion system, like stability control, traction control and enhanced differential performances. In accordance with the equation cited in [2], Fig. 3 shows the schematic diagram of the electric differential system.

\section{THE MOdEL REFERENCE ADAPTIVE SySTEM}

\section{A. Nomenclature}

$v_{d s}\left(v_{q s}\right)=d$-axis ( $q$-axis) stator voltages;

$i_{d s}\left(i_{q s}\right)=d$-axis $q$-axis) stator currents;

$\lambda_{d r}\left(\lambda_{q r}\right)=d$-axis ( $q$-axis) rotor flux linkages;

$\lambda_{d m} \quad=$ Magnetizing $d$-axis flux linkage;

$R_{s}\left(R_{r}\right)=$ Stator (rotor) resistance;

$L_{s}\left(L_{r}\right) \quad=$ Stator (rotor) inductance;

$L_{m} \quad=$ Magnetizing inductance;

$L_{\sigma} \quad=$ Leakage inductance $\left(L_{\sigma}=L_{s}-L_{m}{ }^{2} / L_{r}\right)$;

$\omega_{e}\left(\omega_{r}\right)=$ Stator (rotor) electrical speed;

$\Omega \quad=$ Rotor speed $\left(\omega_{r} / p\right)$;

$\omega_{s l} \quad=$ Slip frequency, $\omega_{s l}=\omega_{\mathrm{s}}-\omega_{r} ;$

$B \quad=$ Motor damping ratio;

$p \quad=$ pole-pair number.

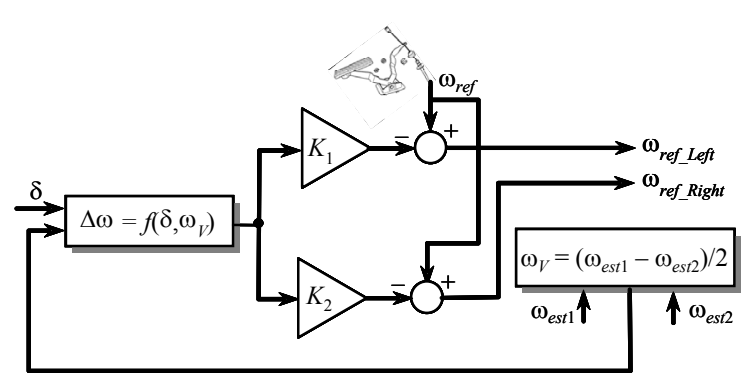

Fig. 3. The EDS block diagram. 


$$
\left\{\begin{array}{l}
k_{1}=\frac{R_{s}}{L_{\sigma}}+\frac{R_{r} L_{m}^{2}}{L_{r}^{2} L_{\sigma}}, k_{2}=\frac{R_{r} L_{m}}{L_{r}^{2} L_{\sigma}}, k_{3}=\frac{L_{m}}{L_{r} L_{\sigma}} \\
k_{4}=\frac{R_{r} L_{m}}{L_{r}}, k_{5}=\frac{R_{r}}{L_{r}}, k_{6}=\frac{1}{L_{\sigma}}, k_{t}=\frac{3}{2} p \frac{L_{m}}{L_{r}}
\end{array}\right.
$$

\section{B. Induction Motor Dynamic Model}

Generally, dynamic modeling of an induction motor drive is performed based on a rotating reference-frame theory and a linear technique.

A system configuration of an induction motor drive is shown in Fig. 4. This motor drive consists of an induction motor, a bang-bang current-controlled Pulse Width Modulated (PWM) inverter, a field-orientation mechanism, a coordinate translator and a speed controller.

The induction motor dynamic model in the synchronously rotating $d-q$ reference frame can be expressed by (1) [7-8].

$$
\left\{\begin{array}{l}
\frac{d}{d t}\left[\begin{array}{c}
i_{d s} \\
i_{q s} \\
\lambda_{d r} \\
\lambda_{q r}
\end{array}\right]=\left[\begin{array}{cccc}
-k_{1} & \omega_{e} & k_{2} & \omega_{r} k_{3} \\
-\omega_{e} & -k_{1} & -\omega_{r} k_{3} & k_{2} \\
k_{4} & 0 & -k_{5} & \omega_{s l} \\
0 & k_{4} & -\omega_{s l} & -k_{5}
\end{array}\right]\left[\begin{array}{c}
i_{d s} \\
i_{q s} \\
\lambda_{d r} \\
\lambda_{q r}
\end{array}\right]+k_{6}\left[\begin{array}{c}
V_{d s} \\
V_{q s} \\
0 \\
0
\end{array}\right] \\
\frac{d \omega_{r}}{d t}=-\frac{B}{J} \omega_{r}-\frac{1}{J}\left(T_{m}-T_{L}\right) \\
T_{m}=k_{t}\left(\lambda_{d r} i_{q s}-\lambda_{q r} i_{d s}\right)
\end{array}\right.
$$

\section{Adaptive Control}

Adaptive control has emerged as a potential solution for implementing high-performance control systems, especially when dynamic characteristics of a plant are unknown, or have large and unpredictable variations. The MRAS achieves robust and high-performance because of the presence of a reference model which specifies the desired performance. The adaptation scheme uses stator voltages and currents, where the reference model output is compared to an adaptive model output.

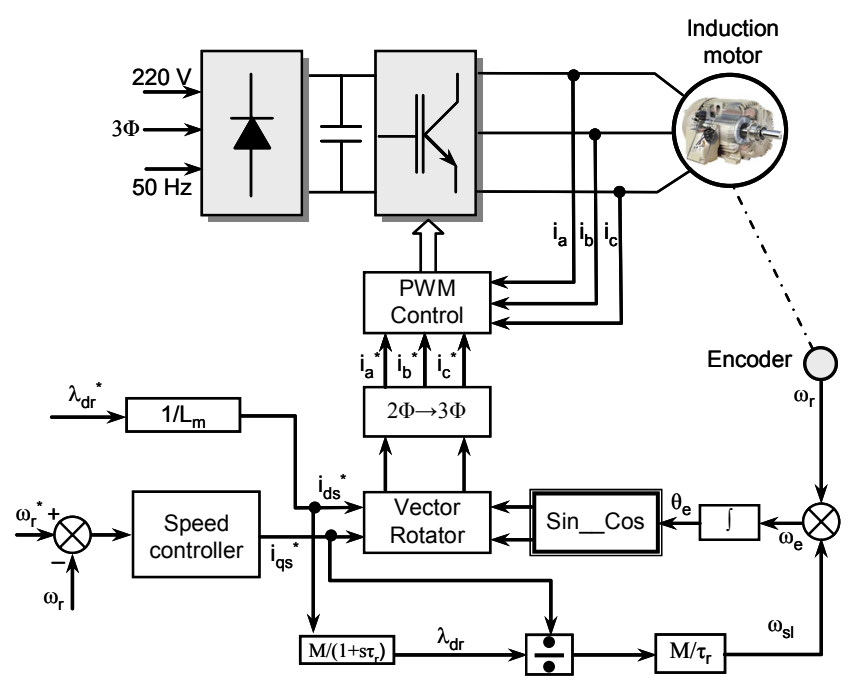

Fig. 4. The direct field-oriented induction motor drive.
Then the rotor speed is estimated based on the difference between these state variables. A number of MRAS-based speed sensorless schemes have been described in the literature for field-oriented induction motor drives [9-12].

The MRAS general block diagram is shown in Fig.5. The stator voltage equation for $v_{d s}$ in the $d-q$ equivalent circuit can be written as

$v_{d s}=R_{s} i_{d s}+L_{s} \frac{d i_{d s}}{d t}+\frac{d \lambda_{d m}}{d t}$

The rotor flux $d$-component can be expressed as

$\lambda_{d r}=\frac{L_{r}}{\lambda_{m}} \lambda_{d m}-L_{r} i_{d s}$

and then $\lambda_{d m}=\frac{L_{m}}{L_{r}}\left(\lambda_{d r}+L_{r} i_{d s}\right)$

Substituting $\lambda_{d m}$ in (2) gives

$v_{d s}=\frac{L_{m}}{L_{r}} \frac{d \lambda_{d r}}{d t}+\left(R_{s}+\sigma L_{s} S\right) i_{d s}$

and $\frac{d \lambda_{d r}}{d t}=\frac{L_{r}}{L_{m}} v_{d s}-\frac{L_{r}}{L_{m}}\left(R_{s}+\sigma L_{s} S\right) i_{d s}$

Similarly, $\lambda_{q r}$ can be expressed as

$\frac{d \lambda_{q r}}{d t}=\frac{L_{r}}{L_{m}} v_{q s}-\frac{L_{r}}{L_{m}}\left(R_{s}+\sigma L_{s} S\right) i_{q s}$

Equations (6) and (7) constitute the reference model or the voltage model. The model calculates the rotor fluxes from the motor stator voltages and currents. The adjustable or adaptive model is constructed using the current flux model equations.

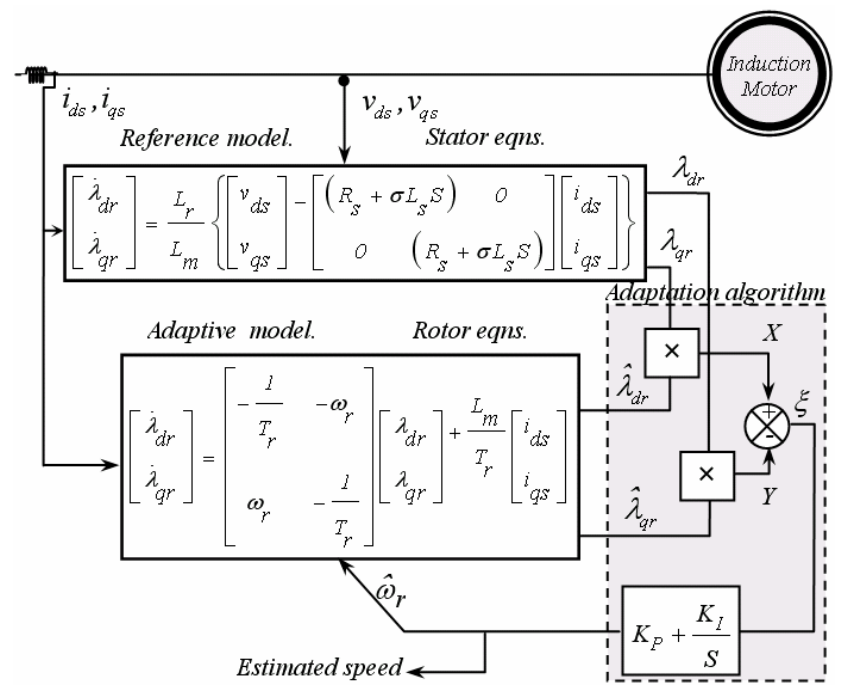

Fig. 5. MRAS block diagram. 
The rotor circuit equations in the $d-q$ synchronously equivalent circuits may be written as

$$
\left\{\begin{array}{l}
\frac{d \lambda_{d r}}{d t}+R_{r} i_{d r}+\omega_{r} \lambda_{q r}=0 \\
\frac{d \lambda_{q r}}{d t}+R_{r} i_{q r}-\omega_{r} \lambda_{d r}=0
\end{array}\right.
$$

Adding $\left(L_{m} R_{r} / L_{r}\right) i_{d s}$ and $\left(L_{m} R_{r} / L_{r}\right) i_{q s}$ on both sides of (8) and substituting

$$
\left\{\begin{array}{l}
\lambda_{d r}=L_{m} i_{d s}+L_{r} i_{d r} \\
\lambda_{q r}=L_{m} i_{q s}+L_{r} i_{q r}
\end{array}\right.
$$

leads to $\left\{\begin{array}{l}\frac{d \lambda_{d r}}{d t}=\frac{L_{m}}{T_{r}} i_{d s}-\omega_{r} \lambda_{q r}-\frac{1}{T_{r}} \lambda_{d r} \\ \frac{d \lambda_{q r}}{d t}=\frac{L_{m}}{T_{r}} i_{q s}+\omega_{r} \lambda_{d r}-\frac{1}{T_{r}} \lambda_{q r}\end{array}\right.$

Hence, the adaptive model may be represented as

$$
\left[\begin{array}{l}
\dot{\lambda}_{d r} \\
\dot{\lambda}_{q r}
\end{array}\right]=\left[\begin{array}{cc}
\frac{-1}{T_{r}} & -\omega_{r} \\
\omega_{r} & \frac{-1}{T_{r}}
\end{array}\right]\left[\begin{array}{l}
\lambda_{d r} \\
\lambda_{q r}
\end{array}\right]+\frac{L_{m}}{T_{r}}\left[\begin{array}{l}
i_{d r} \\
i_{q r}
\end{array}\right]
$$

The above equations give the rotor fluxes as functions of stator currents and rotor speed. Thus, if speed and stator currents are known, the rotor fluxes may be estimated. These equations are defined as the current model for flux estimation or adaptive model. The estimator that does not involve the quantity to be estimated (here the rotor speed $\omega_{r}$ ) is considered as the reference model and the other estimator that includes the rotor speed is regarded as the adjustable model. If parameters and rotor speed values are known, then the outputs of both reference and adjustable models should match. An adaptation algorithm with a PI controller, as shown in Fig. 5, is used to tune the speed so that the error $\xi$ converges to 0 .

While designing the MRAS adaptation algorithm, it is important to take into account the overall system stability and to ensure that the estimated speed will converge to the desired value with satisfactory dynamic characteristics. Using Popov criteria for hyperstability for a globally asymptotically stable system, we can derive the following speed estimation relation [13].

$\hat{\omega}_{r}=\xi\left(K_{p}+\frac{K_{I}}{S}\right)$

where $\xi=X-Y=\hat{\lambda}_{d r} \lambda_{q r}-\lambda_{d r} \hat{\lambda}_{q r}$

The speed estimated from MRAS control is fed back to a speed controller and is compared against the reference speed to get the controlled output.

\section{EXPERIMENTAL TESTS}

Before using the EDS on an EV, the drive performances of the proposed electric differential are evaluated using the experimental test bench shown in Fig. 6 .

The test bench is composed of elements that emulate various loads applied to the $\mathrm{EV}$, operational means of the driver such as the induction motors $(380 \mathrm{~V}, 2.4 \mathrm{~A}, 900 \mathrm{~W}$, $1400 \mathrm{rpm})$, the drive units that control the induction motors using two inverters, a propulsion control chip (the accelerator pedal and the steering wheel) based on a dSPACE DS1103 board. The two high-voltage low-current inverters DMC1500 are designed with discrete semiconductors to seek a flexible and low-cost prototype.

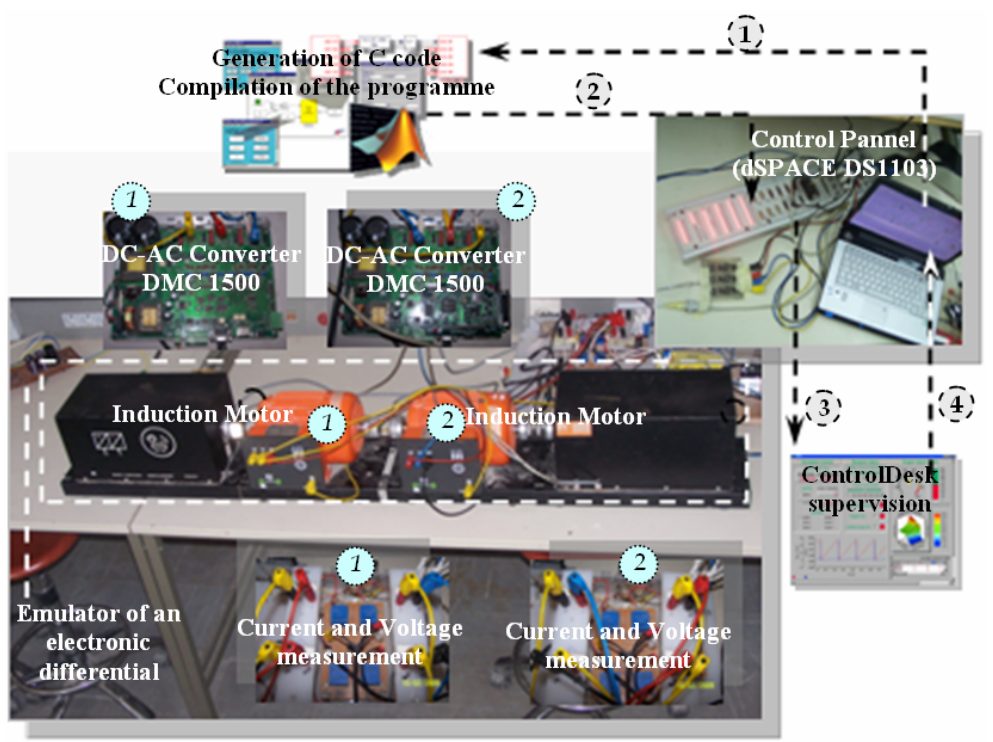

Fig. 6. The experimental test bench. 
To validate the electric differential, a series of tests in different load conditions were performed to emulate different type of traction behavior of a road vehicle. For that purpose, the New European Driving Cycle (NEDC) is used. It consists of four repeated ECE-15 driving cycles and an extra-urban driving cycle (EUDC) (Fig. 7).

We first evaluate the performance of the adaptive observer. The results displayed in Fig. 8 shows then the convergence of the estimated flux towards the references. In this case, the convergence is still guaranteed even if the initial conditions are different from zero.

The ED performances are illustrated by Fig. 9, which shows each wheel speed during steering for $0<t<1180 \mathrm{sec}$. It is obvious that the ED operates satisfactorily according to the complicated series of accelerations, decelerations, and frequent stops imposed by the urban ECE-15 cycle. Moreover, it can be seen that $\omega_{\text {left }}$ and $\omega_{\text {right }}$ are overlapped (beginning with zero steering angle). When the steering angle changes, the speeds $\omega_{\text {left }}$ and $\omega_{\text {right }}$ change too, in order to follow the $\Delta \omega$ imposed by the differential algorithm.

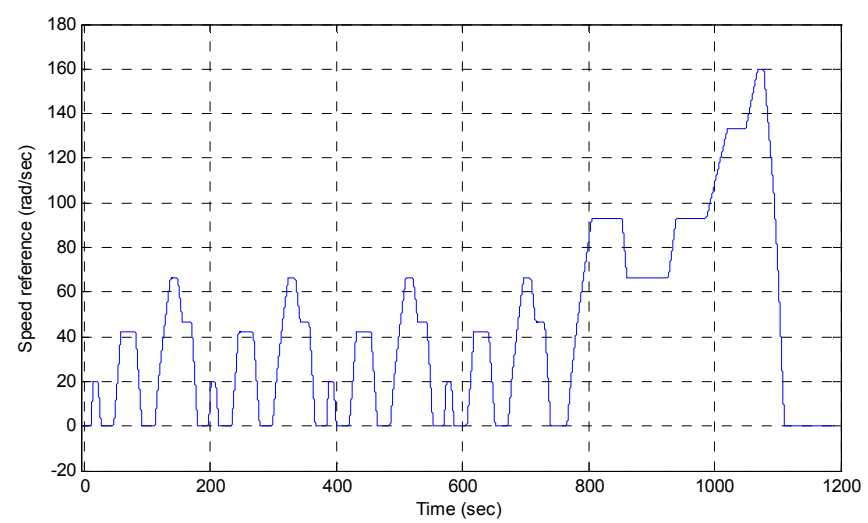

Fig. 7. The NDEC driving cycle.
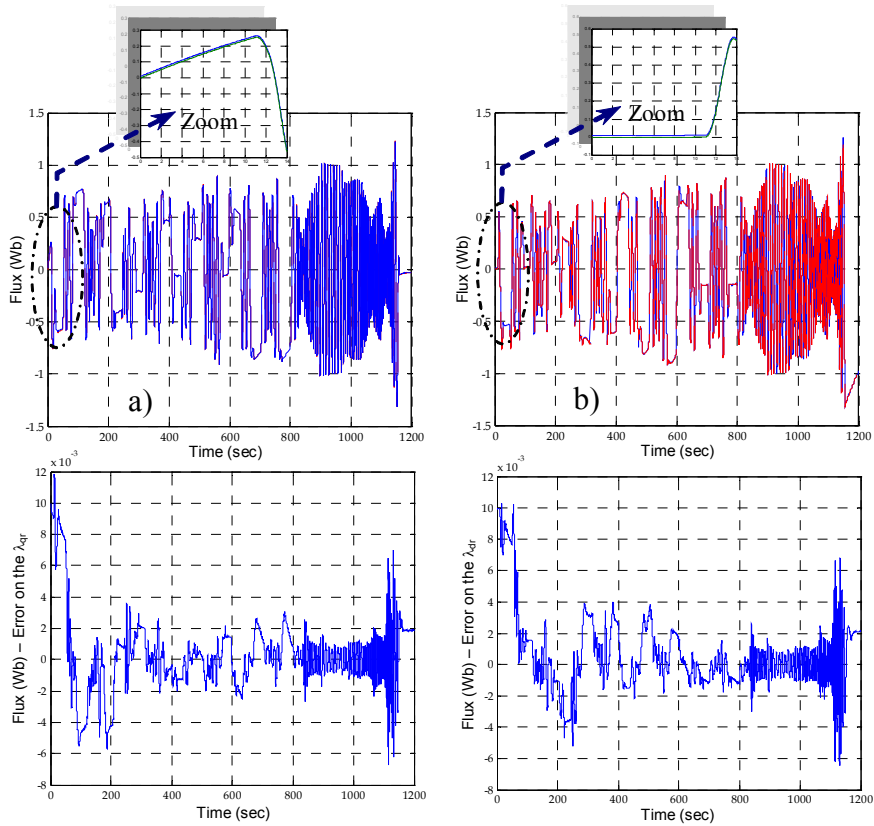

Fig. 8. Convergence of the estimated flux towards the references.

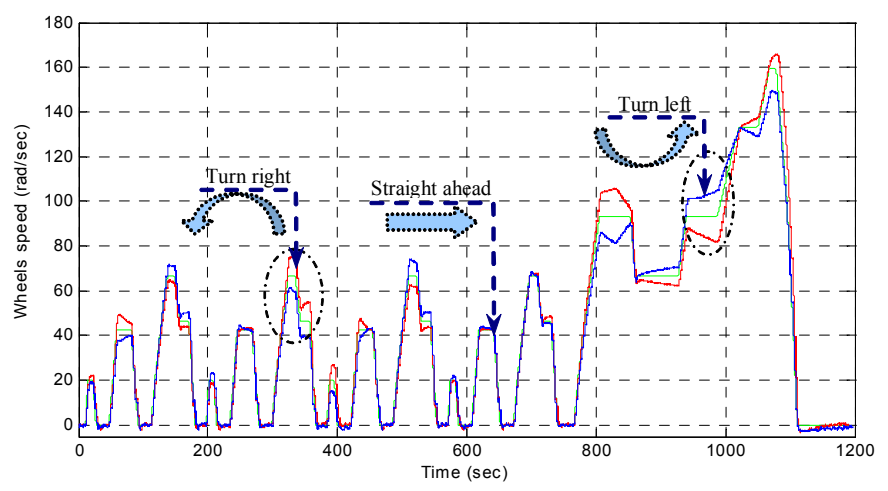

Fig. 9. Estimated, measured and reference wheel speeds.

This experiment shows that the electric differential is able to pull the vehicle forward even if one of the wheels is spinning freely, which would not be the case with a traditional mechanical differential.

In the control systems, the main control inputs were torque and flux references. Operating conditions and sensing variables are considered to be ideal for all the system and the same tests were realized in experiments. Figs. 10 and 11 illustrate the ED emulation dynamics, respectively, the flux $\left(\lambda_{d r}\right)$ and the developed torque for speed sensorless-based MRAS control in each induction motor, with changes in the acceleration pedal position and a varied road profile (rising and downward portions) (Fig. 12). It should be noticed that flux and torque variations are as large as variations of the accelerator pedal and the road profile.

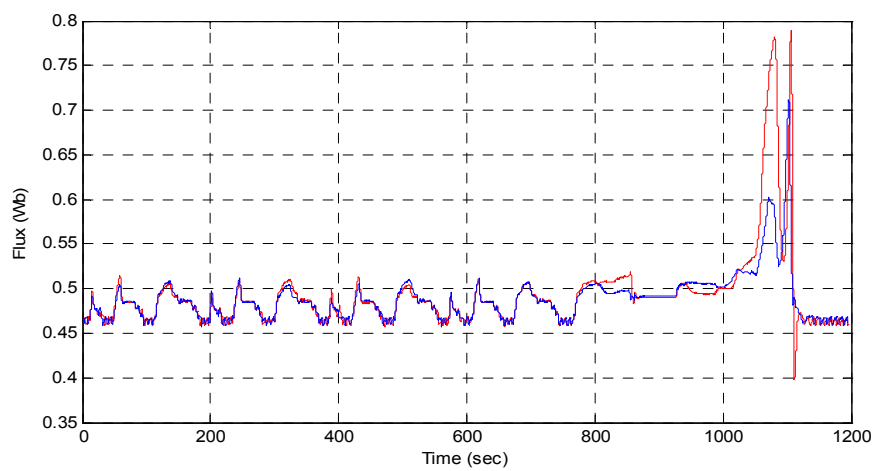

Fig. 10. The induction motors fluxes $\lambda_{d r}$.

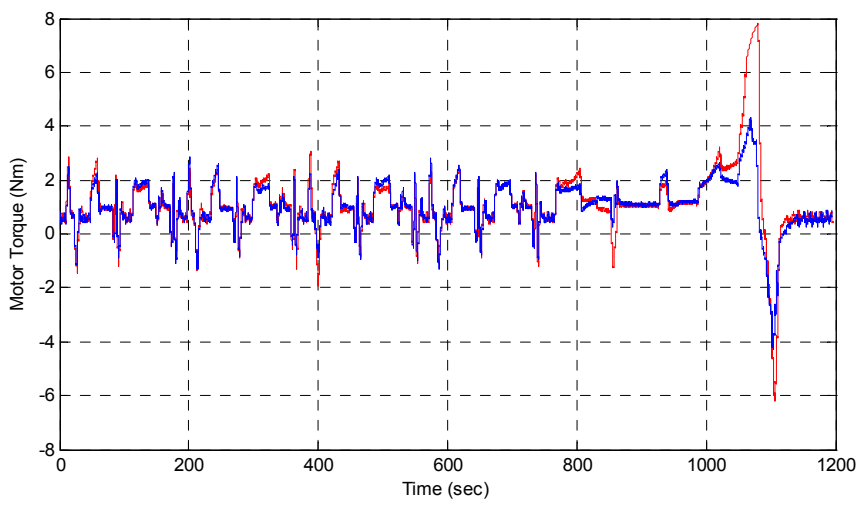

Fig. 11. The induction motors torque. 


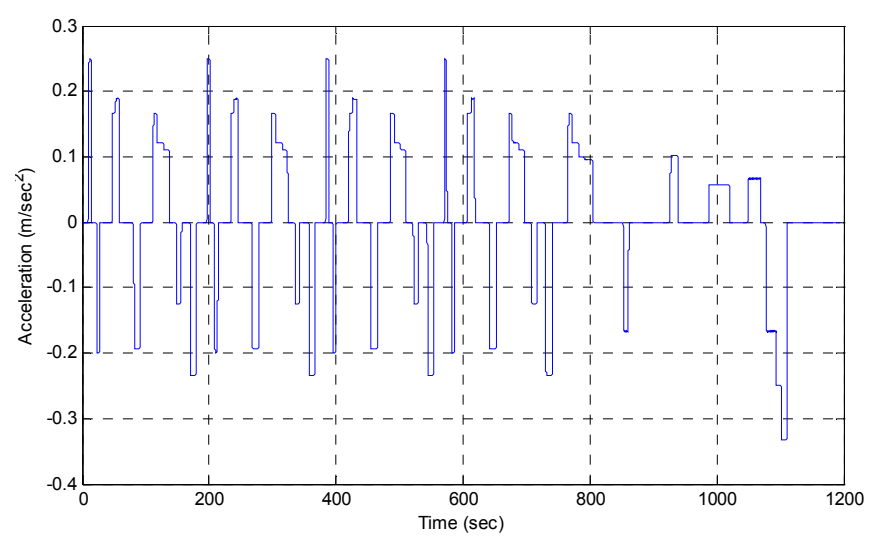

Fig. 12. Acceleration pedal position.

The MRAS speed estimator performances are illustrated by Fig. 13, which shows the measured speed and the estimated value. This figure clearly shows that the estimated speed during this test correctly follows the measured one even at zero-speed.

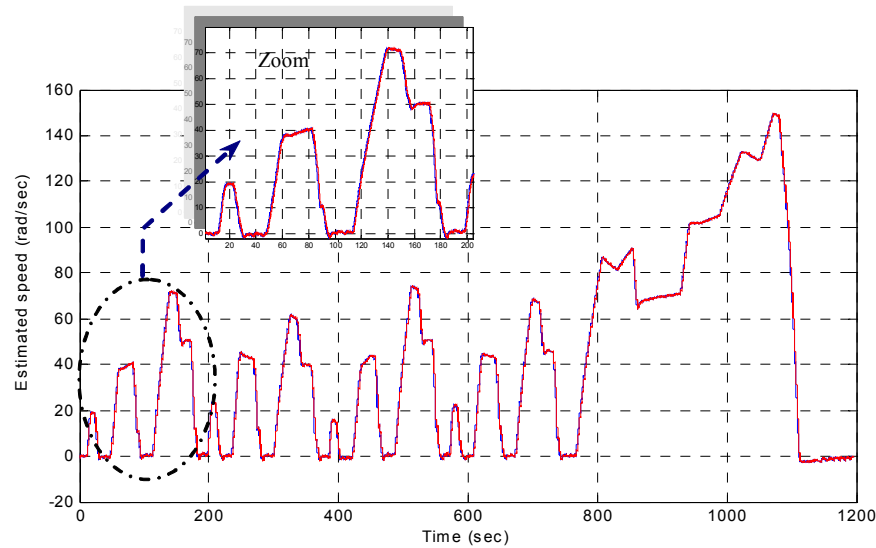

Fig. 13. Estimated and measured speed.

\section{CONCLUSION}

This paper has described the design and implementation of an electric differential for an electric vehicle propulsion system. The control system is evaluated with a rapid prototyping environment (dSPACE DS1103). It has been designed to meet the vehicle requirements (steering and stability) during trajectory changes. A key feature of our implementation is the development of a single chip that incorporates both the Electric Differential and the induction motors control. Experimental results verify and demonstrate the prototype operation with two $0.9 \mathrm{~kW}$ induction motor drives in the powertrain using the NDEC test cycle.
APPENDIX

RATED DATA OF THE TWO TESTED INDUCTION MOTORS

$0.9 \mathrm{~kW}, 50 \mathrm{~Hz}, 380 \mathrm{~V}, 2.4 \mathrm{~A}, 1400 \mathrm{rpm}, 6.14 \mathrm{Nm}, p=2$ $R_{s}=12.75 \Omega, R_{r}=05.15 \Omega, L_{s}=0.43 \mathrm{H}, L_{r}=0.43 \mathrm{H}$ $J=0.0035 \mathrm{kgm}^{2}$

\section{REFERENCES}

[1] N. Mutoh et al., "Electric braking control methods for electric vehicles with independently driven front and rear wheels," IEEE Trans. Industrial Electronics, vol. 54, n², pp. 1168-1176, April 2007.

[2] A. Haddoun et al., "Modeling, analysis and neural network control of an EV Electrical Differential," IEEE Trans. Industrial Electronics, vol. 55, $\mathrm{n}^{\circ} 6$, pp. 2286-2294, June 2008 .

[3] A. Ece Hartavi et al., "Signal interfacing for hybrid electric vehicular electronics and an implementation study," in Proceedings of the IEEE ICVES'08, Columbus, OH (USA), pp. 151-156, September 2008.

[4] R.P. de Castro et al., "A new FPGA based control system for electrical propulsion with electronic differential," in Proceedings of the EPE'07, Aalborg (Denmark), pp. 1-10, September 2007.

[5] S. Gair et al., "Electronic differential with sliding mode controller for a direct wheel drive electric vehicle," in Proceedings of the IEEE ICM'04, pp. 98-103, Istanbul (Turkey), June 2003.

[6] R.E. Colyer et al., "Comparison of steering geometries for multiwheeled vehicles by modelling and simulation," in Proceedings of IEEE $C D C^{\prime} 98$, vol. 3, pp. 3131-3133, December 1998.

[7] T.J. Ren et al., "Robust speed-controlled induction motor drive based on recurrent neural network," Electric Power Systems Research, vol. 76, pp. 1064-1074, 2006

[8] A. Benchaïb et al., "Real-time sliding mode observer and control of induction motor," IEEE Trans. Industrial Electronics, vol. 46, $\mathrm{n}^{\circ} 1, \mathrm{pp}$. 128-138, February 1999.

[9] C. Lascu et al., "Comparative study of adaptive and inherently sensorless observers for variable-speed induction-motor drives," IEEE Trans. Industrial Electronics, vol. 53, n¹, pp. 57-65, February 2006.

[10] S. Bolognani et al., "Parameter sensitivity analysis of an improved open-loop speed estimate for induction motor drives," IEEE Trans. Power Electronics, vol. 23, n 4, pp. 2127-2135, July 2008.

[11] R. Pena et al., "Sensorless control of doubly-fed induction generators using a rotor-current-based MRAS observer," IEEE Trans. Industrial Electronics, vol. 55, $\mathrm{n}^{\circ} 1$, pp. 330-339, January 2008.

[12] K. Ohyama et al., "Comparative analysis of experimental performance and stability of sensorless induction motor drives," IEEE Trans. Industrial Electronics, vol. 53, $\mathrm{n}^{\circ} 1$, pp. 178-186, February 2006.

[13] M. Tomita et al., "New sensorless control for brushless DC motors using disturbance observers and adaptive velocity estimations," IEEE Trans. Industrial Electronics, vol. 45, n², pp. 274-282, April 1998. 